\title{
HISTOPATHOLOGICAL EVALUATION OF ENDOSCOPIC BIOPSIES IN PATIENTS WITH LESIONAL GASTROINTESTINAL TRACT DISORDERS
}

\author{
Anand Shankarao Patil1, Maraudavanan Ramachandran², Rajesh Kumar Mohan³, Kaviraj Mahadevan4, Balamurugan Rangasamy 5 \\ ${ }^{1}$ Associate Professor, Department of Pathology, Sri Manakula Vinayagar Medical College \& Hospital, Madagadipet. \\ 2Professor, Department of General Surgery, Sri Manakula Vinayagar Medical College \& Hospital, Madagadipet. \\ ${ }^{3}$ Post Graduate, Department of Pathology, Sri Manakula Vinayagar Medical College \& Hospital, Madagadipet. \\ ${ }^{4}$ Research Associate, Central Research Laboratory, Sri Manakula Vinayagar Medical College \& Hospital, Madagadipet. \\ ${ }^{5}$ Research Scientist, Central Research Laboratory, Sri Manakula Vinayagar Medical College \& Hospital, Madagadipet.
}

\section{ABSTRACT}

\section{BACKGROUND}

Histopathological examination of endoscopic biopsies is the easiest way to diagnose the gastro intestinal tract (GIT) disorders. This study deals with histopathological evaluation of 60 Gastrointestinal Tract (GIT) endoscopic biopsies carried out between January 2014 to February 2015.

\section{MATERIALS AND METHODS}

Flexible endoscope was used to retrieve biopsy material, which was then fixed with $10 \%$ formalin and further processed with Hematoxylin and Eosin (H and E), Periodic Acid-Schiff (PAS), Giemsa, Acid-Fast Stain (AFS), Alcian Blue and examined by histopathologists.

\section{RESULTS}

Stomach ( 45 cases) was the most common site for biopsy. Chronic non-specific gastritis was the most common lesion diagnosed in the stomach and in GIT (24 cases). Colon was the second most common site for biopsy. Colitis/proctitis was diagnosed in 6 out of 12 colonic biopsies. Malignant lesions diagnosed were 8 adenocarcinoma of stomach, 2 squamous cell carcinoma of esophagus and 1 adenocarcinoma colon. Out of all 60 cases $48(80 \%)$ were non-neoplastic and 12 (20\%) were neoplastic cases.

\section{CONCLUSION}

We conclude that endoscopic biopsy for diagnosing GIT lesions is the gold standard and indispensable for diagnosis and management.

\section{KEYWORDS}

Endoscopy, Gastro Intestinal Tract (GIT), Biopsy, Gastritis.

HOW TO CITE THIS ARTICLE: Patil AS, Ramachandran M, Mohan RK, et al. Histopathological evaluation of endoscopic biopsies in patients with lesional gastrointestinal tract disorders. J Evolution Med Dent Sci 2016;5(1):01-03, DOI: 10.14260/jemds/2016/1

\section{INTRODUCTION}

Patients presenting with a variety of Gastrointestinal Tract (GIT) symptoms frequently attend Outpatient Departments (OPD) and require thorough investigations to arrive at a confirmatory diagnosis.

Endoscopic examination of GIT is the simple and convenient investigation to offer some clue to the diagnosis. ${ }^{1}$ The main concern is the presence or absence of malignancy. ${ }^{2}$ Endoscopy is very useful for selection of the site of suspected lesion. ${ }^{3}$

Endoscopic examination can be carried out at OPD with minimal discomfort to the patient. ${ }^{4}$ Endoscopic biopsy coupled with subsequent histopathological examination of the suspected lesion will help tremendously to arrive at final diagnosis.

Financial or Other, Competing Interest: None.

Submission 14-12-2015, Peer Review 15-12-2015,

Acceptance 29-12-2015, Published 01-01-2016.

Corresponding Author:

Dr. Balamurugan Rangasamy,

Research Scientist \& Incharge,

Central Research Laboratory,

Sri Manakula Vinayagar Medical College \& Hospital,

Puducherry-605107, India.

E-mail: bala.rangasamy5@gmail.com

DOI:10.14260/jemds/2016/1
This will also lead to early detection of malignancy which will have great impact on timely management of the patient.5,6

The present study deals with the histopathological and clinical evaluation of 63 endoscopic biopsies of suspected GI lesions.

\section{MATERIALS AND METHODS}

The present hospital based cross-sectional study was carried out in Sri Manakula Vinayagar Medical College and Hospital, from January 2014 to February 2015 for interpretation of endoscopic biopsies taken from GIT lesions.

The flexible endoscope-Olympus CV150, was used to perform endoscopic examination and biopsy was taken from suspected lesions. Biopsy material was fixed with 10\% formalin and forwarded for processing in histopathology lab.

Biopsy material was subjected to automated processing and then embedded in paraffin with mucosal surface facing the cut end of the block; $5 \mu$ thick sections were prepared. Sections were stained with Hematoxylin and Eosin (H and E), Periodic Acid-Schiff (PAS), Giemsa, Acid-Fast Stain (AFS), Alcian Blue wherever required. These biopsies were examined by the histopathologists in the department for definitive histopathological diagnosis. 


\section{RESULTS}

A total of 1069 patients underwent endoscopic examination, out of which 63 patients had suspected lesions. Of all the 63 patients, $40(63.5 \%)$ were males and $23(36.5 \%)$ were females with male-to-female ratio being 1.7:1. The age distribution ranged from 10 years to 74 years. In the 12 malignant neoplastic lesions of the GIT, the youngest patient was 40 years old and oldest was 67 years old. Male: Female ratio among neoplastic cases was 1:1.

Although, endoscopic biopsies were performed at the site where there was strong indication, 3 cases were inconclusive by histopathology. These 3 cases were excluded from this study. Out of the 60 diagnosed cases, 48 (80\%) were non-neoplastic and $12(20 \%)$ were neoplastic cases. In one case there were unremarkable changes in histopathology.

Gastritis (Acute/chronic/acute on chronic) was diagnosed in 24 (40\%) cases. Figure 2 depicts acute on chronic gastritis. Gastric ulcer was diagnosed in 7 (11.66\%) cases, out of which 2 cases were associated with intestinal metaplasia. Helicobacter pylori induced gastritis was seen in a single case. Gastric polyp was diagnosed in $2(3.33 \%)$ cases (Figure 4$)$, which consisted of one hyperplastic and inflammatory each.

In neoplastic lesions, 8 were adenocarcinoma stomach (Figure 5) and 2 were squamous cell carcinoma of the oesophagus. One case of villous adenoma of stomach was reported.

One case each of acute on chronic oesophagitis, Barrett's oesophagus and oesophageal candidiasis (Figure 3) was reported.

Colitis/proctitis was diagnosed in $6(10 \%)$ cases. Ulcerative colitis and colonic polyp was reported in 2 (3.33\%) cases each. Adenocarcinoma of colon was diagnosed in 1 case.

\section{DISCUSSION}

The study was conducted from January 2014 to February 2015 comprised of 1069 endoscopies, out of which 63 biopsies were taken from GIT. Gastric biopsies comprised 45 (71.4\%), duodenal 1 (1.6\%), colonic $12(19 \%)$ and $5(8 \%)$ oesophageal biopsies. Most common site for GI biopsy was from stomach, which correlates with similar studies on GIT biopsies.7,8

\section{Age and Gender Distribution}

In this study predominant age group was 51-60 years, which comprises of 17 patients $(26.9 \%)$ which was found to be correlating with a study by Krishnappa Rashmi, et al. ${ }^{9}$ Males formed majority of the cases (63.5\%), which was similar with trends in other studies.

\section{Oesophageal Lesions}

In the 2 squamous cell carcinomas of the oesophagus, one was moderate to poorly differentiated and the other was poorly differentiated. Other oesophageal lesions were Barrett's oesophagus, Gastro-oesophageal reflux disease and oesophageal candidiasis.

\section{Gastric Lesions}

The main bulk of biopsies in this study were from stomach. Out of 45 gastric biopsies, $36(80 \%)$ were non-neoplastic and 9 (20\%) were neoplastic diagnoses. Most common lesion in the GIT was by chronic non-specific gastric ulcer in 24 of the all 60 biopsies (40\%) diagnosed. This observation was similar with that in the literature. ${ }^{10}$
Out of 9 neoplastic lesions, 8 were adenocarcinoma of stomach and the remaining one was villous adenoma stomach.

\section{Colonic Lesions}

Colitis/proctitis (Non-specific) was most common lesion in the colon (6), which was $50 \%$ of colon biopsies. Ulcerative colitis was reported in 2 cases. Out of 2 colonic polyps, 1 was hyperplastic and other was inflammatory. Adenocarcinoma comprised of 1 case. One granulomatous lesion (Epithelioid granuloma) of colon also was reported.

\section{CONCLUSION}

Endoscopic biopsy is a convenient outpatient procedure which when combined with biopsy from suspected site or lesion can be a powerful tool for definitive diagnosis of GIT lesions.

Non-neoplastic GIT conditions form predominant pathology in this study. Chronic non-specific gastritis outnumbered all other lesions. Stomach was the most common site for malignant GIT tumours.

Although endoscopy alone gives some clue to the diagnosis of GIT lesions, biopsy with histopathological examination is indispensable for diagnosis and subsequent management and also has been proved to be the gold standard.

\section{REFERENCES}

1. Loffeld R, Liberov B, Dekkers PEP. The changing prevalence of upper gastrointestinal endoscopic diagnoses: a single-centre study. Neth J Med 2012 Jun; 70(5):222-6.

2. Hendricks D, Parker MI. Oesophageal cancer in Africa. IUBMB Life. 2002; 53:263-268.

3. Tsuji S, Doyama H, Tsuji K, Tsuyama S, Tominaga K, Yoshida N, et al. Preoperative endoscopic diagnosis of superficial non-ampullary duodenal epithelial tumors including magnifying endoscopy. World J Gastroenterol 2015 Nov 7; 21(41):11832-41.

4. Axon ATR, Bell GD, Jones RH, et al. Guidelines on appropriate indications for upper gastrointestinal endoscopy. British Medical Journal 1995; 310:853-856.

5. Tytgat GNJ. Role of endoscopy and biopsy in the workup of dyspepsia. Gut 2000; 50(4):13-16.

6. Graham DY, Rakel RE, Fendrick AM, Go MF, Marshall BJ, Peura DP, et al. Scope and consequences of peptic ulcer disease: How important is asymptomatic Helicobacter pylori infection?

Postgraduate Medicine 1999; 105:106-119.

7. Kim CG, Choi IJ, Lee JY, Cho SJ, Nam BH, Kook MC, et al. Biopsy site for detecting Helicobacter pylori infection in patients with gastric cancer. J Gastroenterol Hepatol 2009 Mar; 24(3):469-74.

8. Kimura K. Gastritis and gastric cancer. Asia. Gastroenterol Clin North Am 2000 Sep; 29(3):609-21.

9. Rashmi, Krishnappa, et al. A study on histopathological spectrum of upper gastrointestinal tract endoscopic biopsies. International Journal of Medical Research and Health Sciences 2013; 2.3:418-424.

10. Pailoor K, Sarpangala MK, Naik RC. Histopathological diagnosis of gastric biopsies in correlation with endoscopy-a study in a Tertiary Care Center. Adv Lab Med Int 2013; 3(2):22-31. 


\begin{tabular}{|c|c|}
\hline Age Group & No. of Cases - 63 \\
\hline $0-10$ & 1 \\
\hline $11-20$ & 2 \\
\hline $21-30$ & 1 \\
\hline $31-40$ & 11 \\
\hline $41-50$ & 15 \\
\hline $51-60$ & 17 \\
\hline $61-70$ & 12 \\
\hline 71-80 & 4 \\
\hline \multicolumn{2}{|c|}{ Table 1: Age Distribution of Cases } \\
\hline
\end{tabular}

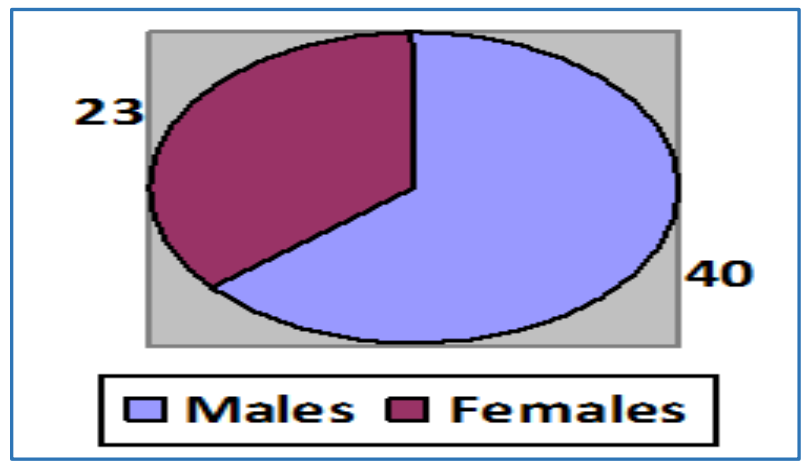

Fig. 1: Gender Distribution of Cases

\begin{tabular}{|c|c|}
\hline Diagnosis & $\begin{array}{c}\text { No. of } \\
\text { Cases -63 }\end{array}$ \\
\hline Chronic non-specific gastritis & 24 \\
\hline Benign gastric ulcer/Chronic gastric ulcer & 7 \\
\hline Gastric polyp & 2 \\
\hline Helicobacter pylori gastritis & 1 \\
\hline Granulomatous lesion-colon & 1 \\
\hline Proctitis/Colitis & 6 \\
\hline Ulcerative colitis & 2 \\
\hline Colonic polyp & 2 \\
\hline Acute on chronic oesophagitis & 1 \\
\hline Oesophageal candidiasis & 1 \\
\hline Barrett's oesophagus & 1 \\
\hline Gastric villous adenoma & 1 \\
\hline Adenocarcinoma stomach & 8 \\
\hline Adenocarcinoma colon & 1 \\
\hline Squamous cell carcinoma oesophagus & 2 \\
\hline Unremarkable histology (stomach) & 3 \\
\hline Table 2: Distribution of Cases by Diagnosis \\
\hline
\end{tabular}

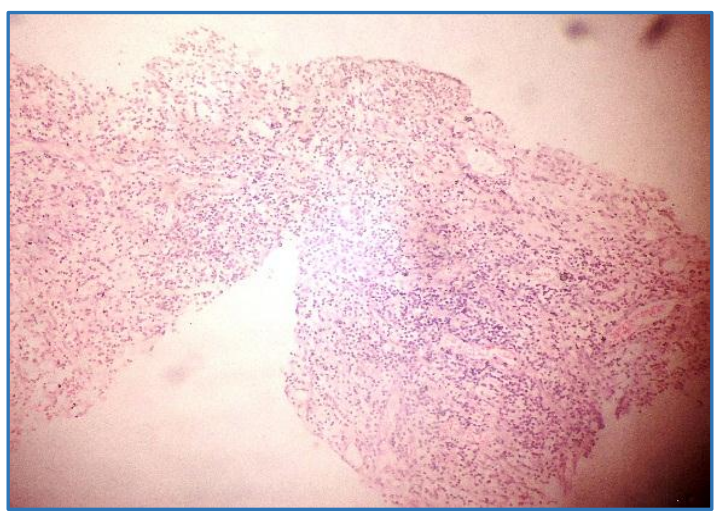

Fig. 3: Chronic Oesophagitis (H\&E, 50x)

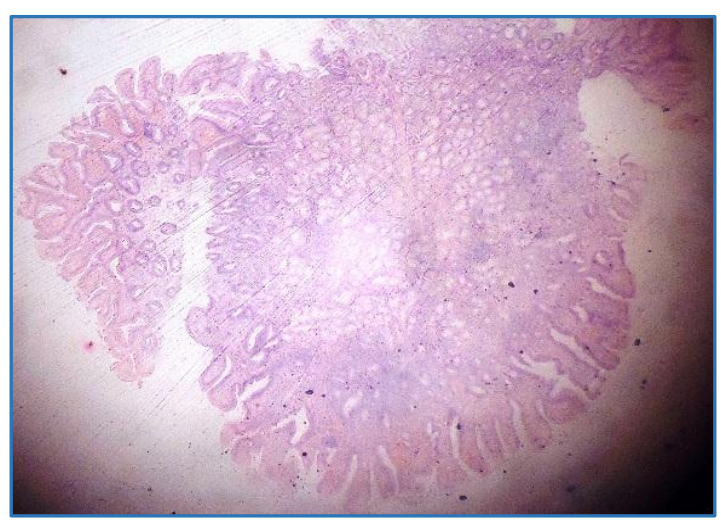

Fig. 4: Hyperplastic Gastric Polyp (H\&E, 50x)

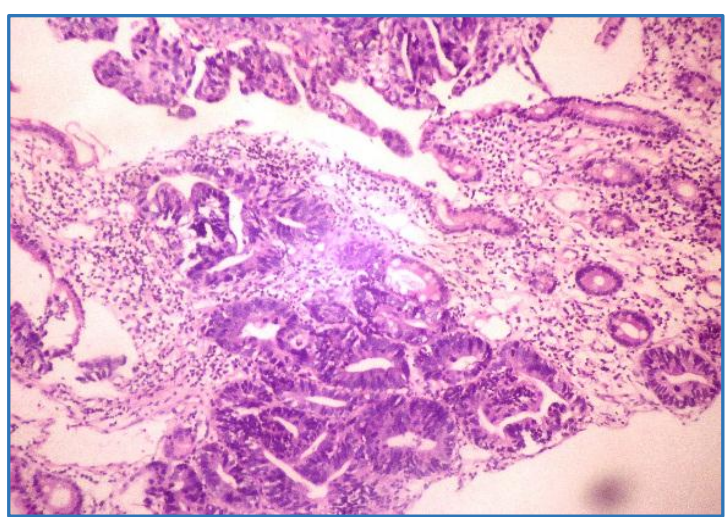

Fig. 5: Moderate-to-well-differentiated Adenocarcinoma Stomach (H\&E, 400x)

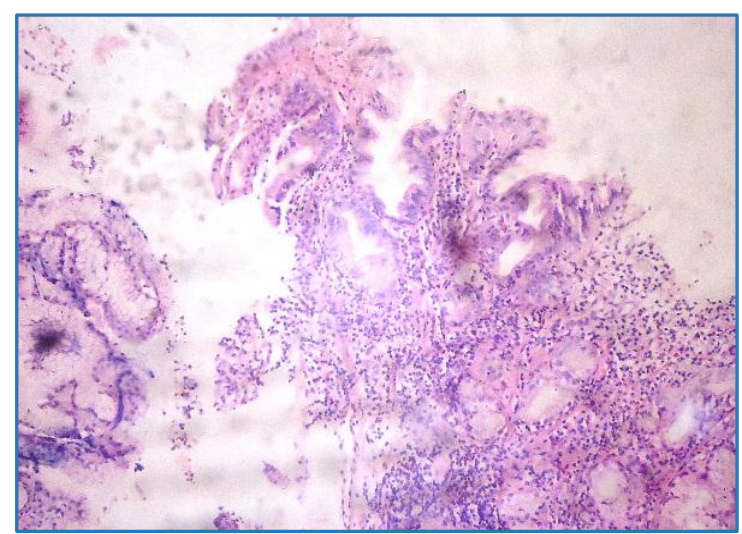

Fig. 6: Ulcerative Colitis (H\&E, 100x) $g$ 